\title{
Factors influencing the population structure of Aedes aegypti from the main cities in Cambodia
}

\author{
C Paupy ${ }^{1}$, N Chantha ${ }^{2}$, J-M Reynes ${ }^{3}$ and A-B Failloux ${ }^{1,4}$ \\ ${ }^{1}$ Insectes et Maladies Infectieuses (formerly, Ecologie des Systèmes Vectoriels), Paris, France; ${ }^{2}$ National Malaria Center, 372 boulevard \\ Monivong, Phnom Penh, Cambodia; ${ }^{3}$ Unité de Virologie, Institut Pasteur du Cambodge, 5 boulevard Monivong, Phnom Penh, Cambodia
}

\begin{abstract}
A population genetic analysis was conducted on 47 Aedes aegypti collections from Cambodia. Genetic differentiation at seven polymorphic isoenzyme loci was analysed by starch gel electrophoresis. Low $\left(\mathrm{F}_{\mathrm{ST}}=0.024\right)$ but significant $\left(P<10^{-6}\right)$ differentiation was found when all samples were considered. Whatever the grouping of samples tested,
\end{abstract}

differentiation remained significant but low. The role of human activities (ie insecticide treatments or water storage practices) and environmental factors (ie rainfall) in shaping mosquito differentiation are discussed.

Heredity (2005) 95, 144-147. doi:10.1038/sj.hdy.6800698; published online 22 June 2005

Keywords: Aedes aegypti; isoenzyme; genetic differentiation; Cambodia

\section{Introduction}

Dengue fever (DF) and dengue haemorrhagic fever (DHF) are an important public health issue in tropical and subtropical areas. The frequency of DF has increased dramatically since the first description of DHF in the mid-1950s (Gubler, 2002). A total of 50-100 million cases of DF and several hundred thousand cases of DHF occur annually over 100 countries including many in SouthEast Asia (Lam, 1998).

The main vector of dengue viruses, Aedes aegypti, was probably inadvertently introduced from Africa into Asia at the end of the 19th Century, by the increased trade and shipping. The insects' establishment and spread in Asia coincided with the first dengue epidemics in urban areas (Smith, 1956). Ae. Aegypti is closely associated with humans. The species is well adapted to urban environments, which provide numerous opportunities for bloodmeals (Scott et al, 1997) and larval breeding sites (Strickman and Kittayapong, 1993). Water storage containers (particularly concrete jars with a capacity of 1001 or more) represent the most frequent larval habitat in Cambodia. They sustain high larval infestation rates throughout the year (Ngan Chantha, personal communication). Indeed, in 1990, Ae. aegypti comprised more than $40 \%$ of indoor-resting mosquitoes in Phnom Penh (Kohn, 1990).

Cambodia is located in the Southwest of the Indochinese peninsula and bounded on the west by Thailand, on the north by Laos, on the east by Vietnam and to the south by the gulf of Thailand. Most Cambodians (85\% of the 11.4 million inhabitants) live in rural areas on the

Correspondence: Dr A-B Failloux, Institut Pasteur, UP Génétique moléculaire des Bunyaviridés, 25-28 rue du Docteur Roux, 75724 Paris Cedex 15, France. E-mail: afaillou@pasteur.fr

${ }^{4}$ Current address: Génétique moléculaire des Bunyaviridés, Institut Pasteur, 25 rue du Dr Roux, 75724 Paris Cedex 15, France.

Received 15 March 2005; accepted 21 March 2005; published online 22 June 2005 fertile central plains of the Mekong-Tonlé basin. Cambodia's climate is governed by two monsoons: the cool, dry north-eastern monsoon from November to February, and the humid south-western monsoon from May to October.

Though Cambodia has regularly been confronted with dengue since 1962, more severe and recurrent outbreaks have been observed in the last 20 years (Rathavuth et al, 1997). In 1990 and 1995, Cambodia was subjected to two major epidemics with 7241 cases (331 deaths) and 10208 cases (424 deaths), respectively. However, it was in 1998 that the worst epidemic was recorded: 16216 DHF cases and 475 deaths (Ngan et al, 1998). In 2001, 10264 DHF cases, 195 of them fatal, were reported (Ngan Chantha, personal communication). The National Dengue Control Programme of the Ministry of Health implemented insecticide spraying and mass applications of the larvicide temephos, in drinking water containers leading to a long-term larval control.

We analysed the genetic structure of Ae. aegypti populations in four cities differing in their level of urbanisation and insecticide treatments, both of which are known to shape mosquito genetic structure (Huber et al, 2002; Mousson et al, 2002). In the present study, we addressed the following questions: (1) is the genetic structure of Ae. aegypti populations similar in the different cities, (2) what are the main factors driving mosquito genetic differentiation and (3) what are the implications of our findings in the control of dengue transmission in Cambodia.

\section{Materials and methods}

\section{Mosquito samples}

In total, 47 Ae. aegypti samples were collected in different localities in the four main cities of Cambodia from February to April 2001 (Supplementary Table 1, Figure 1): 22 in Phnom Penh (Figure 1), nine in Kampong Cham, eight in Kampong Som (Sihanoukville), and eight in Siem Reap. Samples that consisted of larvae or pupae 


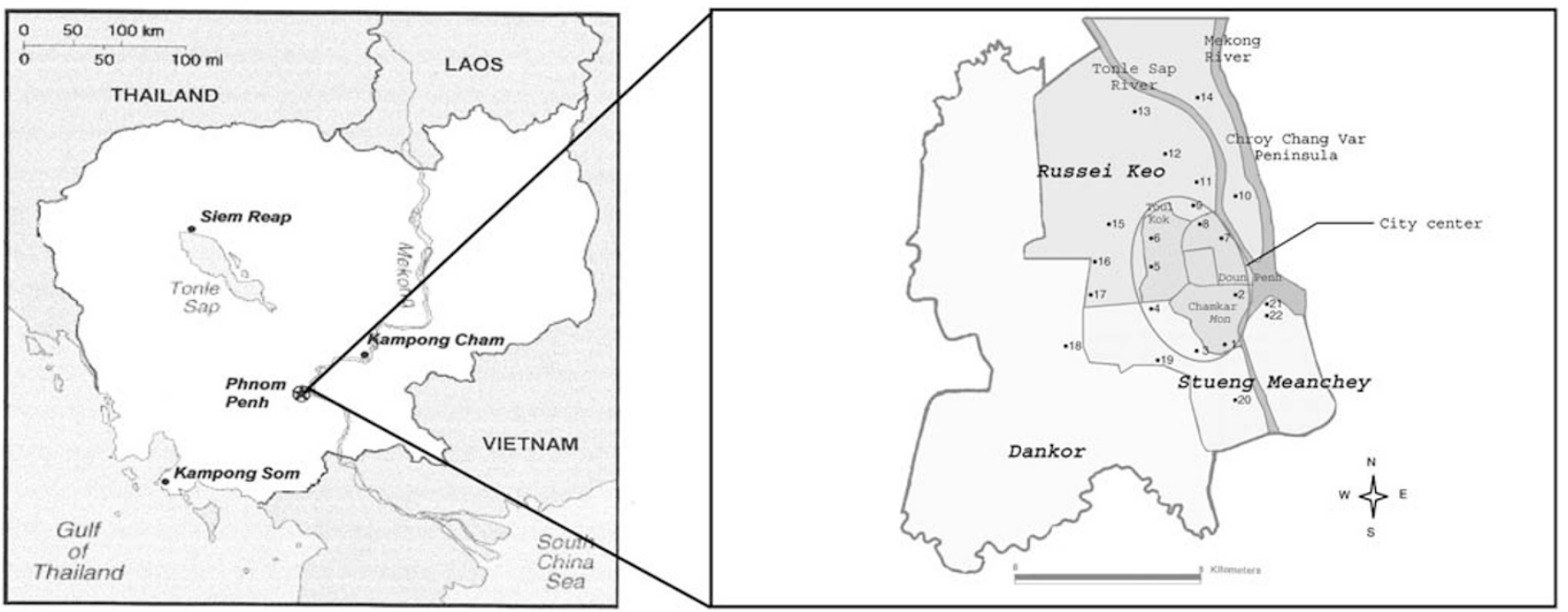

Figure 1 Map of Cambodia and Phnom Penh showing the location of Aedes aegypti samples collected in 2001.

were reared until the imago stage. Adults were kept for analysis of enzyme polymorphism.

\section{Isoenzyme polymorphism}

Each individual mosquito was ground in $25 \mu \mathrm{l}$ of distilled water. The sample was centrifuged $(15000 \mathrm{rpm}$ for $4 \mathrm{~min}$ at $+4^{\circ} \mathrm{C}$ ) and the supernatant was loaded on a starch gel using the Tris-Maleate-EDTA ( $\mathrm{pH}$ 7.4) buffer system. Seven enzyme systems were studied: glutamate oxaloacetate transaminase (Got-1 and Got-2), glycerol-phosphate dehydrogenase (G-3-pdh), hexokinase (Hk-1, Hk-2 and $\mathrm{Hk}-3)$, malate dehydrogenase (Mdh), malate dehydrogenase (NADP) (Mdhp-1), phosphoglucoisomerase (Pgi) and phosphoglucomutase (Pgm) (for more details, see Paupy et al, 2000). An Ae. aegypti strain developed from an isofemale lineage was used in control lanes as a marker for protein mobility. For field-collected samples, alleles were numbered according to their mobility compared to that of the most common allele obtained at each locus in the control strain.

\section{Genetic analysis}

Deviations from Hardy-Weinberg proportions, genotypic linkage disequilibrium and genetic differentiation were tested using the GENEPOP software (version 3.3). (Raymond and Rousset, 1995). Hardy-Weinberg proportions were tested by the probability test proposed by Haldane (1954). The overall significance of multiple tests for each locus or for each sample was estimated by Fisher's combined probability test (Fisher, 1970). Heterozygote deficit or excess were tested using an exact test procedure (Rousset and Raymond, 1995). Genotypic association between pairs of loci was tested for each sample using Fisher's test contingency tables. $\mathrm{F}_{\mathrm{IS}}$ and $\mathrm{F}_{\mathrm{ST}}$ were calculated according to the formula described by Weir and Cockerham (1984). Genetic differentiation across populations was assessed by calculating $P$-value for the $F_{\mathrm{ST}}$ estimate. The overall significance of multiple tests was estimated by Fisher's combined probability test (Fisher, 1970). The significance level for multiple tests was adjusted by the sequential method of Bonferroni (Holm, 1979).

\section{Results}

\section{Hardy-Weinberg equilibrium}

Out of 158 tests run, six significant deviations from Hardy-Weinberg equilibrium were detected after application of Bonferroni procedure: Hk-2/PP9 $\left(\mathrm{F}_{\mathrm{IS}}=+0\right.$. 793), Mdhp-1/PP8 ( $\left.\mathrm{F}_{\mathrm{IS}}=+1\right), \mathrm{Mdhp}-1 / \mathrm{PP} 14\left(\mathrm{~F}_{\mathrm{IS}}=+1\right)$, Mdhp-1/PP15 $\left(\mathrm{F}_{\mathrm{IS}}=+1\right)$, Pgi/PP2 $\left(\mathrm{F}_{\mathrm{IS}}=+0.850\right)$ and Pgi/PP8 ( $F_{I S}=+0.793$ ) (Supplementary Table 2). HardyWeinberg equilibrium was also tested assuming that the alternative hypothesis $\mathrm{H} 1$, was a heterozygote deficit (H0: random mating). All deviations detected were due to a heterozygote deficit. When considering global tests (ie all loci for each sample), three samples showed significant heterozygote deficit: PP2, PP8 and PP17.

\section{Linkage disequilibrium}

Genotypic disequilibrium was tested between pairs of loci for each sample. Out of 549 possible combinations, 42 significant nonrandom associations were detected (after Bonferroni's sequential test; $P<0.05$ ): 13 concerning the combination $\mathrm{Hk}-1 / \mathrm{Hk}-2,13$ for $\mathrm{Hk}-1 / \mathrm{Hk}-3,13$ for $\mathrm{Hk}-2 / \mathrm{Hk}-3$, one for G-3-pdh/Hk-1, one for G-3-pdh/ Hk-2 and one for G-3-pdh-Hk-3 (data not shown). Therefore, the loci Hk-1, Hk-3 and G-3-pdh were excluded from the data set.

\section{Population differentiation}

When considering all 47 samples (Table 1), significant differentiation was observed $\left(\mathrm{F}_{\mathrm{ST}}=0.024\right.$. and $\left.P<10^{-6}\right)$.

Each locus showed significant $\mathrm{F}_{\mathrm{ST}}$ values.

When comparing samples between cities (ie, Kampong Cham (KC), Kampong Som (KS), Phnom Penh (PP) and Siem Reap (SR)), all combinations were highly significant $\left(\mathrm{F}_{\mathrm{ST}}\right.$ ranging from 0.015 to 0.030 ) whatever the geographic distances separating the localities (Table 1).

Within cities significant genetic differentiation (Table 1; $P<10^{-6}$ ) was detected in all cases except for the eight samples collected in Kampong Som $\left(\mathrm{F}_{\mathrm{ST}}=-0.001\right.$, $P>0.05)$. It may be relevant that Kampong Som suffers the heaviest rainfalls in the country (eg $7210.5 \mathrm{~mm}$ for 1999-2000 compared to Phnom Penh with $3689 \mathrm{~mm}$ ). 
Table 1 Aedes aegypti differentiation in Cambodia

\begin{tabular}{|c|c|c|c|c|c|c|c|c|c|}
\hline \multirow[t]{2}{*}{ Comparison } & \multirow[t]{2}{*}{$N$} & \multicolumn{8}{|c|}{$F_{\mathrm{st}}$} \\
\hline & & Got-1 & Got-2 & $H K-2$ & $M d h p-1$ & $M d h$ & Pgm & $P g i$ & All loci \\
\hline All samples & 47 & 0.009 & $0.013^{* * *}$ & $0.080^{* * *}$ & $-0.002^{* *}$ & $0.021^{* * *}$ & $0.022^{* * *}$ & $0.019^{* * *}$ & $0.024^{* * *}$ \\
\hline \multicolumn{10}{|l|}{ Between cities } \\
\hline SR-KC & 17 & 0 & $0.043^{* *}$ & $0.103^{* * *}$ & - & $0.023^{* * *}$ & $0.026^{* * *}$ & $0.015^{* * *}$ & $0.030^{* * *}$ \\
\hline SR-PP & 30 & 0.006 & $0.012^{* * *}$ & $0.090^{* * *}$ & $-0.002^{*}$ & $0.027^{* * *}$ & $0.021^{* * *}$ & $0.017^{* * *}$ & $0.028^{* * *}$ \\
\hline SR-KS & 16 & 0.009 & $0.031^{* * *}$ & $0.127^{* * *}$ & - & $0.014^{* * *}$ & $0.020^{* * *}$ & 0.009 & $0.024^{* * *}$ \\
\hline PP-KC & 31 & $0.010^{*}$ & $0.007^{* *}$ & $0.039^{* * *}$ & $-0.003^{*}$ & $0.025^{* * *}$ & $0.024^{* * *}$ & $0.018^{* * *}$ & $0.024^{* * *}$ \\
\hline PP-KS & 30 & 0.011 & $0.082^{* * *}$ & $0.045^{* * *}$ & -0.002 & $0.019 * * *$ & $0.019 * * *$ & $0.018^{* * *}$ & $0.019 * * *$ \\
\hline KC-KS & 17 & 0.013 & 0.009 & $0.019^{* *}$ & - & $0.011^{* * *}$ & $0.021^{* * *}$ & $0.011^{*}$ & $0.015^{* * *}$ \\
\hline \multicolumn{10}{|l|}{ Within cities } \\
\hline Kampong Cham & 9 & - & - & $0.021^{* *}$ & - & $0.021^{* * *}$ & $0.026^{* * *}$ & $0.018^{* *}$ & $0.022^{* * *}$ \\
\hline Kampong Som & 8 & 0.013 & 0.009 & 0.004 & - & 0.005 & 0.008 & -0.005 & -0.001 \\
\hline Phnom Penh & 22 & $0.010^{*}$ & $0.007^{* *}$ & $0.046^{* * *}$ & $-0.003^{*}$ & $0.027^{* * *}$ & $0.021^{* * *}$ & $0.014^{* * *}$ & $0.024^{* * *}$ \\
\hline Siem Reap & 8 & 0 & $0.043^{* *}$ & $0.115^{* * *}$ & - & $0.029 * * *$ & $0.021^{* * *}$ & $0.014^{*}$ & $0.036^{* * *}$ \\
\hline \multicolumn{10}{|l|}{ Phnom Penh } \\
\hline City center & 9 & - & 0.006 & $0.036^{* * *}$ & -0.001 & $0.025^{*}$ & $0.022^{* * *}$ & $0.009^{* *}$ & $0.022^{* * *}$ \\
\hline Suburbs & 13 & 0.010 & $0.008^{* *}$ & $0.050^{* * *}$ & -0.002 & $0.028^{* * *}$ & $0.022 * * *$ & $0.018^{* * *}$ & $0.026^{* * *}$ \\
\hline \multicolumn{10}{|l|}{ Within suburbs } \\
\hline South & 4 & - & - & -0.002 & - & 0.007 & 0.002 & 0.005 & 0.005 \\
\hline West & 4 & - & 0.012 & 0.030 & 0 & 0.016 & 0.087 & $0.023^{* *}$ & $0.015^{* * *}$ \\
\hline North & 5 & 0.010 & -0.002 & $0.055^{* * *}$ & -0.001 & $0.058^{* * *}$ & $0.021^{* *}$ & 0.013 & $0.053^{* * *}$ \\
\hline North (without peninsula) & 3 & - & 0.003 & $0.055^{* * *}$ & - & $0.013^{* * *}$ & 0.033 & 0.016 & $0.024^{* * *}$ \\
\hline \multicolumn{10}{|l|}{ Between suburbs } \\
\hline South-west & 8 & - & $0.016^{*}$ & $0.026^{*}$ & -0.002 & 0.009 & 0.009 & $0.022^{*}$ & $0.011^{* * *}$ \\
\hline South-north & 9 & 0.010 & 0.006 & $0.058^{* * *}$ & -0.002 & $0.037^{* * *}$ & $0.028^{* * *}$ & $0.012^{*}$ & $0.032^{* * *}$ \\
\hline West-north & 9 & 0.011 & $0.004^{*}$ & $0.049^{* * *}$ & -0.002 & $0.038^{* * *}$ & $0.021^{* * *}$ & $0.018^{* * *}$ & $0.030^{* * *}$ \\
\hline
\end{tabular}

N: sample size; PP: Phnom Penh; KC: Kampong Cham; KS: Kampong Som; SR: Siem Reap. In bold when $P$ was significant ( $<0.05),{ }^{*} P<0.01$, ${ }^{* *} P<0.001,{ }^{* * *} P<0.0001$.

There is no significant association between geographic distance and genetic differentiation.

Within Phnom Penh the samples from the city centre were highly and significantly differentiated $\left(\mathrm{F}_{\mathrm{ST}}=0.022\right.$, $P<10^{-6}$ ) and isolation by distance was detected (slope $b=0.013, P<0.05)$. In the suburbs, genetic differentiation was lower in the south $\left(\mathrm{F}_{\mathrm{ST}}=0.005, P>0.05\right)$ and in the west $\left(F_{\mathrm{ST}}=0.015, P<10^{-6}\right)$ and highest in the north $\left(\mathrm{F}_{\mathrm{ST}}=0.053, P<10^{-6}\right)$ mainly due to the two samples from Chroy Chang Var peninsula (PP10 and PP14). With these samples excluded, $\mathrm{F}_{\mathrm{ST}}=0.024\left(P<10^{-6}\right)$.

The highest differentiation between suburbs was that between the south and the north (Table 1: $\mathrm{F}_{\mathrm{ST}}=0.032$ ).

\section{Discussion}

The spatial survey of genetic variability of Ae. aegypti in Cambodia underlines the low level of genetic differentiation compared to that detected in Thailand (Mousson et al, 2002) or from Vietnam (Tran et al, 1999; Huber et al, 2002).

Climatic factors such as rainfall are important in generating breeding sites. The severe and periodic rainfalls in Kampong Som (Sihanoukville) could fill containers, which accumulate at the vicinity of houses (Trips, 1972) and are used by females to oviposite. The abundance of breeding sites could enhance Ae. aegypti movement and genetic exchange and reduce genetic differentiation. A similar explanation may apply in reverse in Siem Reap, where the high genetic differentiation coincides with low rainfall. Temporary breeding sites disappear and a population bottleneck may have led to a reduction of polymorphism. This same pattern was very marked in populations from Ho Chi Minh City (Huber et al, 2002).

In addition to climatic factors, human factors such as insecticide application and water-storage practice can affect mosquito genetic structure. In Seam Reap, a city famous for its Angkorian temples, there is massive insecticide use in the numerous hotels accommodating the flood of visitors. Mosquito populations were highly differentiated implicating insecticide treatments as a factor producing subdivision (McCauley, 1991). Conversely, Kampong Som, a city essentially visited by Cambodians, has less insecticide treatment and thus, $A e$. aegypti is less genetically differentiated.

Phnom Penh is currently developing and making up for the time lost during the civil war. Out of more than one million people living in Phnom Penh province, 570000 are settled in the urban area. The uncontrolled immigration and consequent urbanisation of the suburbs has led to severe shortages in the water supply, thus compelling people to store water. The water storage containers prove most of the larval breeding sites for Ae. aegypti (about 80\%; Ngan Chantha, personal communication). The low genetic differentiation detected in all but the northern suburbs could be attributed to the high densities of Ae. aegypti and increased gene flow. The 
higher differentiation in the northern suburbs can be explained by the Tonle Sap river, which may act as a barrier to gene flow. It isolates samples PP10 and PP14 (located in the Chroy Chang Var peninsula) from the others (see Figure 1).

Similarly the differentiation between northern and southern populations could be explained if the city centre is a barrier to gene flow. Piped water supply is available almost everywhere in the city centre reducing open water storage and hence the density of Ae. aegypti (Kohn, 1990).

The relatively low genetic differentiation observed amongst all Cambodian Ae. aegypti could indicate the rapid spreading of populations and thus, of genes of interest such as those controlling the susceptibility to insecticides. Such wide dispersal would dictate that vector control campaigns should be implemented simultaneously over large areas.

Insecticide treatments of breeding sites and source reduction are both recommended to limit dengue epidemics. However, these stategies could also potentially promote vector dispersal as a result of reducing available oviposition sites.

Our study gives us a general insight into of Ae. aegypti ecology in the main Cambodian cities. Future studies should address whether these patterns persist throughout the year and, in particular, if there are differences between the rainy and at the dry season. For such purposes, more population genetic studies must be supported.

\section{Acknowledgements}

This research was supported by the program ACIP 'Action Concertée des Instituts Pasteur' (no 41204). We are grateful to 'Fondation de France, Jeunesse Internationale' for providing a 6-month fellowship to M Paupy during his stay in Cambodia. We thank Nadia Ayad, Laurence Mousson and Regine Villeret for technical assistance. We would also like to thank the staff of the 'Unité de Virologie' (Institut Pasteur du Cambodge), CNM (National Malaria Centre) and the municipality of Phnom Penh for their invaluable help in mosquito collections. We are indebted to Professor J-L Durosoir from Pasteur Institute in Paris, and to Professor $Y$ Buisson, Director of the Pasteur Institute of Cambodia, for their constant support.

\section{References}

Fisher RA (1970). Statistical Methods for Research Workers, 14th edn. Olivier and Boyd: Edinburg.
Gubler DJ (2002). Epidemic dengue/dengue hemorrhagic fever as a public health, social and economic problem in the 21st century. Trends Microbiol 10: 100-103.

Haldane JBS (1954). An exact test for randomness of mating. J Genet 52: 631-635.

Holm S (1979). A simple sequentially rejective multiple test procedure. Scand J Stat 6: 65-70.

Huber K, Luu Le L, Tran Huu H, Ravel S, Rodhain F, Failloux AB (2002). Genetic differentiation of the dengue vector, Aedes aegypti (Ho Chi Minh City, Vietnam) using microsatellite markers. Mol Ecol 11: 1629-1635.

Kohn M (1990). A survey on indoor resting mosquito species in Phnom Penh, Kampuchea. Folia Parasit 37: 165-174.

Lam SK (1998). Emerging Infectious diseases - Southeast Asia. Emerg Infect Dis 4: 145-147.

McCauley DE (1991). Genetics consequence of local population extinction and recolonization. Trends Ecol Evol 6: 5-8.

Mousson L, Vazeille M, Chawprom S, Prajakwong S, Rodhain F, Failloux AB (2002). Genetic structure of Aedes aegypti populations in Chiang Mai (Thailand) and relation with dengue transmission. Trop Med Int Health 7: 865-872.

Ngan C, Guyant P, Hoyer S (1998). Control of DHF outbreak in Cambodia, 1998. Dengue Bull 22 (http://w3.whosea.org).

Paupy C, Vazeille-Falcoz M, Mousson L, Rodhain F, Failloux AB (2000). Aedes aegypti in Tahiti and Moorea (French Polynesia): isoenzyme differentiation in the mosquito population according to human population density. Am J Trop Med Hyg 62: 217-224.

Rathavuth H, Vaughn DW, Minn K, Nimmannitya S, Nisalak A, Raengsakulrach B et al (1997). Hemorrhagic fever in Cambodia is caused by dengue viruses: evidence of transmission of all four serotypes. Southeast Asian J Trop Med Public Health 28: 120-125.

Raymond M, Rousset F (1995). GENEPOP (version 1.2): population genetics software for exact tests and ecumenicism. J Hered 86: 248-249.

Rousset F, Raymond M (1995). Testing heterozygote excess and deficiency. Genetics 140: 1413-1419.

Scott TW, Naksathit A, Day JF, Kittayapong P, Edman JD (1997). A fitness advantage for Aedes aegypti and the viruses it transmits when females feed only on human blood. Am J Trop Med Hyg 57: 235-239.

Smith CEG (1956). The history of dengue in tropical Asia and its probable relationship to the mosquito Aedes aegypti. J Trop Med Hyg 59: 243-251.

Strickman D, Kittayapong P (1993). Laboratory demonstration of oviposition by Aedes aegypti (Diptera: Culicidae) in covered water jars. J Med Entomol 30: 947-949.

Tran K T, Vazeille-Falcoz M, Mousson L, Tran Huu H, Rodhain F, Nguyen Thi $\mathrm{H}$ et al (1999). Aedes aegypti in Ho Chi Minh City (Vietnam): susceptibility to dengue 2 virus and genetic differentiation. T Roy Soc Trop Med Hyg 93: 581-586.

Trips M (1972). Seasonal change in the larval populations of Aedes aegypti in two biotopes in Dar es Salaam, Tanzania. $B$ World Health Organ 47: 245-255.

Weir BS, Cockerham CC (1984). Estimating F-statistics for the analysis of population structure. Evolution 38: 1358-1370.

Supplementary Information accompanies the paper on Heredity website (http://www.nature.com/hdy) 